\title{
PELAKSANAAN TUGAS DAN FUNGSI PEMERINTAH DALAM USAHA KESEJAHTERAAN SOSIAL ANAK
}

\author{
Budi Astuti \\ Pegawai Negeri Sipil Salatiga \\ budiastuti4567@gmail.com
}

\begin{abstract}
The research objective was to determine the process of social welfare services carried out by the Woro Wiloso Salatiga Social Rehabilitation Center in realizing children's social welfare, and to find out the efforts taken by the Woro Wiloso Social Rehabilitation Center in overcoming obstacles in social services This research methodology uses the approach of juridical sociology with descriptive of research type. The method of collecting data uses observation and interview. The method of analyze data uses qualitative description. The writer applied the theory of good governance and public service to observe whether or not the undertaking of social service in the social service office "Woro Wiloso" Salatiga has fulfilled the aspect and function of good governance and public service as the efforts in improving the children welfare to reach the success of the development of social welfare in Central Java.
\end{abstract}

Keyword: Children welfare, public service, and good governance;

\section{A. Pendahuluan}

Konsep Negara Kesejahteraan Pancasila Negara atau Pemerintah berkewajiban untuk mengatur dan mengarahkan masyarakat sebagai satu kesatuan atau keluarga. Khususnya saat ini bangsa Indonesia sudah memasuki globalisasi ekonomi dan hukum. ${ }^{1}$ Maka untuk menjamin terpenuhinya hak atas kebutuhan dasar warga negara, penyelenggaraan kesejahteraan sosial secara komprehensif dan professional serta perlindungan masyarakat maka dibentuk peraturan

1 Meta Suryani, Anis Mashdurohatun, Penegakan Hukum Terhadap Eksistensi Becak Bermotor Umum (Bentor) Berdasarkan Undang-Undang Nomor 22 Tahun 2009 Tentang Lalu Lintas Dan Angkutan Jalan, Jurnal Pembaharuan Hukum, Volume III No. 1 Januari - April 2016. HIm.21-38 
per Undang-undangan yang mengatur tentang kesejahteraan sosial, Peraturan itu sekarang terwujud dalam Undang-undang selanjutnya disebut UU No. 11 Tahun 2009 tentang Kesejahteraan Sosial.

Pasal 1 ayat (1) UU No. 11 tahun 2009 menyebutkan: "Kesejahteraan Sosial ialah Kondisi terpenuhinya kebutuhan material, spiritual dan sosial warga Negara agar dapat hidup layak dan mampu mengembangkan diri, sehingga dapat melaksanakan fungsi sosialnya."

Pada ayat (2) menyebutkan : "Penyelenggaraan Kesejahteraan Sosial adalah upaya yang terarah dan terpadu dan berkelanjutan yang dilakukan Pemerintah, pemerintah daerah dan masyarakat dalam bentuk pelayanan sosial guna memenuhi kebutuhan dasar setiap warga Negara, yang meliputi rehabilitasi sosial, jaminan sosial, pemberdayaan sosial dan perlindungan sosial "

Menurut teori kesejahteraan yang merupakan salah satu teori dasar dari pengertian kepentingan umum masyarakat pada tubuh administrasi negara, mengajarkan bahwa kepentingan umum yang terutama adalah kesejahteraan. Sejahtera berarti bahwa kebutuhankebutuhan utama daripada kehidupan manusia dalam masyarakat dapat dipenuhi dengan semurah-murahnya dan secepat-cepatnya. Kebutuhan pokok itu adalah : (a) makan; keputusan dan tindakan pejabat-pejabat penguasa jangan sampai membuat warga masyarakat susah mencari makan, (b) kesehatan dan (c) kesempatan kerja (employment); keputusan dan tindakan para pejabat penguasa jangan sampai menimbulkan pengangguran secara langsung atau tidak langsung 2

Di Negara kita permasalahan kesejahteraan sosial masih banyak bermunculan tak kunjung henti, masalah-masalah sosial tersebut antara lain : anak terlantar, anak nakal, balita terlantar, anak

2 S.Prajudi Atmosudirdjo, 1983, Hukum Administrasi Negara, Ghalia, Indonesia, Jakarta, h.31 
jalanan, tuna susila, gelandangan, pengemis, korban penyalah gunaan narkotika, wanita dan lanjut usia yang diperlakukan salah atau korban kekerasan, penyandang cacat, jompo terlantar, keluarga miskin, keluarga yang kondisi perumahan dan lingkungan tidak layak, keluarga bermasalah sosial, psikologis, korban bencana alam dsb. Dari masalahmasalah sosial tersebut yang sering dijumpai dewasa ini oleh Negara kita adalah banyaknya masalah anak terlantar. Data Departemen Sosial Republik Indonesia Tahun 2006 menunjukkan jumlah anak terlantar di Indonesia mencapai 2.815.393 anak. Dari data tersebut menunjukkan Negara kita masih harus berbenah diri dalam mengatasi masalah anak terlantar. $^{3}$

Untuk menjamin pemenuhan hak warga negara akan kebutuhan mendasar, penyelenggaraan kesejahteraan sosial secara komprehensif dan professional serta perlindungan masyarakat, Pemerintah membentuk Undang-Undang Nomor 11 tahun 2009 Tentang Kesejahteraan Sosial. Namun dalam kenyataan masih ada banyak masalah kesejahteraan sosial yang harus ditangani diantaranya yaitu masalah kesejahteraan sosial anak-anak terlantar di Jawa Tengah menunjukkan Tahun 2010 sejumlah 36.859 anak. $^{1}$

Pelayanan kesejahteraan sosial oleh Balai Resos Woro Wiloso Salatiga merupakan pelayanan publik sebagai salah satu perwujudan dari fungsi aparatur Negara sebagai abdi masyarakat disamping sebagai abdi Negara. Pelayanan publik oleh birokrasi publik ini dimaksudkan untuk mensejahterakan masyarakat (warga Negara) dari suatu Negara kesejahteraan (welfare state) yaitu sebagai pemberian pelayanan (melayani) keperluan orang atau masyarakat yang mempunyai kepentingan pada oragnisasi / lembaga itu sesuai dengan

\footnotetext{
${ }^{3}$ Oedzilla,blogsot.com/2009/10/al.htm/

1 www.prov.go.id.Warta daerah-Centra Java,16 April 2010, Data Penyandang Masalah Kesejahteraan Sosial
} 
aturan pokok dan tata cara yang telah ditetapkan. ${ }^{2}$

\section{B. METODE PENELITIAN}

Berdasarkan tujuan penelitian di atas, metode pendekatan pada penelitian ini adalah metode pendekatan yuridis sosiologis, dengan pertimbangan permasalahan yang diteliti adalah mengenai hubungan aspek sosial pendidikan terhadap faktor yuridis. ${ }^{2}$ Pendekatan yuridis sosiologis merupakan suatu pendekatan penelitian terhadap efektifitas hukum, maka relevansinya hukum tidak dikonsesikan sebagai suatu gejala normatif yang otonom, tetapi suatu institusi sosial yang secara riil berkaitan dengan variabel-variabel sosial. Secara eksplisit dapat diperjelas bahwa metode pendekatan sosiologis merupakan penelitian yang melihat dan menganalisis tentang bekerjanya hukum dalam tataran kenyataan. ${ }^{3}$

C. HASIL PENELITIAN DAN PEMBAHASAN

\section{a. Legalitas, Kedudukan, Tugas pokok dan Fungsi Balai Resos} Woro Wiloso Salatiga

Berdasarkan Peraturan Gubernur Jawa Tengah No.: 111 Tahun 2010 tentang Organisasi dan Tata Kerja Unit Pelaksana Teknis pada Dinas Sosial Provinsi Jawa Tengah tanggal 1 November 2010, maka Panti Asuhan Woro Wiloso Salatiga dengan Satuan Kerjanya ( Satker ) yaitu Satker Panti Asuhan Taman Harapan dan Wiloso Tomo Salatiga, berdasarkan Peraturan Gubernur Jawa Tengah No. 111 Tahun 2010 tentang Organisasi dan Tata Kerja Unit Pelaksana Teknis Pada Dinas Sosial Provinsi Jawa Tengah mulai 1 Januari 2011 terjadi perubahan nomenklatur menjadi Balai

2) Joko Widodo, 2001, Good Governance Akuntabilitas Dan Kontrol Birokrasi Pada Era Desentralisasi Dan Otonomi Daerah, Insan Cendekia, Surabaya, h.269

2 Lexy J. Moleong. 2000. Metodologi Penelitian Hukum. Citra Aditya Bakti. Bandung. h. 11.

3 Soerjono Soekanto, 1984, Pengantar Penelitian Hukum, Universitas Indonesia Pers, Jakarta, h. 51. 
Rehabilitasi Sosial ( Balai Resos ) "Woro Wiloso " Salatiga dan Unit Rehabilitasi Sosial ( Unit Resos ) Taman Harapan dan Wiloso Tomo Salatiga

Balai Rehabilitasi Sosial Woro Wiloso Salatiga mempunyai tugas pokok melaksanakan sebagian teknis operasional dan / atau kegiatan teknis penunjang Dinas Sosial di bidang pelayanan dan Rehabilitasi sosial dengan menggunakan pendekatan multi pelayanan, terhadap sasaran garapan / penerima manfaat pelayanan sejumlah 20 anak balita terlantar dan 160 anak terlantar usia sekolah.

Proses Pelayanan Kesejahteraan Sosial Anak

1. Proses Pelayanan kesejahteraan sosial terhadap Penerima Manfaat Anak Terlantar Usia Sekolah , meliputi ${ }^{4)}$ :

a) Tahap Pendekatan Awal (Intake Process )

Kegiatan ini dilakukan menjelang akhir tahun pendidikan sekitar bulan Mei S/d awal Juni setiap tahunnya, yang meliputi ;

* Sosialisasi Program Pelayanan

Dalam rangka penjangkauan calon penerima manfaat dan untuk mensosialisasikan tentang Tugas dan Fungsi Balai Rehabilitasi Sosial Woro Wiloso Salatiga, maka dilakukan sosialisasi ke daerah- daerah melalui kegiatan penyuluhan sosial yang dilakukan penyuluh Sosial, Pekerja Sosial dan staf teknis Balai Rehabilitasi Sosial Woro Wiloso Salatiga .

* Penjaringan calon penerima manfaat

Setelah sosialisasi dilaksanakan, mulai dilakukan penerimaan pendaftaran calon penerima manfaat yang mendaftar baik secara langsung oleh orang tua / keluarga anak atau melalui perangkat desa atau lembaga pendidikan tempat anak

4 ) Wawancara dengan Valentino Waas, S.Sos, selaku Kepala Balai Resos Woro Wiloso Salatiga , Tgl. 20 Februari 2013 
sekolah ataupun kondisi keterlantaran anak yang ditemukan oleh pekerja sosial / pegawai Balai Resos Woro Wiloso di masyarakat.

* Seleksi Calon Penerima Manfaat

Kegiatan seleksi ini dilakukan dengan mengadakan kunjungan rumah / home visit ke rumah calon penerima manfaat untuk mengetahui kondisi riil anak dan keluarga baik secara ekonomi, sosial dan budaya, latar belakang keterlantaran anak serta sumber potensi yang dapat digunakan sebagai faktor pendukung untuk penanganan anak lebih lanjut.

* Penerimaan Calon Penerima Manfaat

Konferensi kasus ( CC ) dilakukan untuk menganalisa hasil kunjungan rumah / home visit terhadap calon penerima manfaat dan keluarga. Bagi calon penerima manfaat yang diterima dilakukan registrasi ulang untuk kepentingan administrasi pelayanan dan perencanaan program pelayanan selanjutnya.

2) Tahap Pengungkapan dan Pemahaman masalah (Assessment) Setelah anak diterima sebagai penerima manfaat dilakukan Assessment oleh pekerja sosial. Kegiatan ini dilakukan untuk mengetahui permasalahan dan kondisi yang lebih kompleks pada anak, keluarga dan lingkungannya serta untuk mengetahui kebutuhan, potensi anak yang dapat digunakan untuk menentukan pelayanan kesejahteraan sosial yang tepat untuk anak.

3) Tahap Perencanaan Program Pelayanan (Plan of Treatment) Perencanaan program pelayanan di Balai Resos Woro Wiloso Salatiga, meliputi ; 
1) Kegiatan Pelayanan Penyantunan (Pelayanan Kesejahteraan Sosial Dasar); untuk pemenuhan kebutuhan dasar sehari-hari penerima manfaat yang meliputi; makan, pakaian, tempat tinggal, pendidikan, kesehatan dan agama

2) Pelaksanaan pelayanan dalam bentuk kegiatan yang disesuaikan dengan kebutuhan, karakteristik dan permasalahan kelayan, seperti; Bimbingan Fisik, Kesehatan dil.

3) Kegiatan Pasca Pelayanan (Termination)

4) Monitoring dan Evaluasi terhadap proses pelayanan dan pencapaian hasil pelayanan.

4) Tahap Pelaksanaan Program Pelayanan ( Treatment )

a) Pelayanan Penyantunan ${ }^{5)}$

Pelayanan yang diberikan dalam kegiatan penyantunan merupakan pemenuhan kebutuhan dasar anak sehari-hari yang terdiri dari pemenuhan kebutuhan : Makan, Pakaian, Tempat tinggal , Kesehatan, Agama

b) Pelayanan dan Rehabilitasi Sosial ${ }^{6}$ )

1)Pendidikan Formal anak - anak penerima manfaat usia sekolah menempuh pendidikan formal di lembaga pendidikan umum sesuai dengan kebutuhan dan jenjang pendidikan anak dari tingkat SD, SLTP dan SLTA.

c) Kegiatan pelayanan yang sesuai dengan kebutuhan, karakteristik dan permasalahan penerima manfaat yang dilaksanakan untuk mempersiapkan kemandirian dan sikap mental anak yang berkualitas, seperti ;

5 ) wawancara dengan Sochibi,SE, selaku Kasi Penyantunan Balai Resos Woro Wiloso Salatiga, Tgl. 22 Fbuari 2013

6 ) wawancara dengan Sardono, S.Sos, selaku Kasi Pelayanan \& Rehabsos. Balai Resos Woro Wiloso Salatiga, Tgl. 22 Februari 2013 
1. Bimbingan Fisik \& Kesehatan; Olah Raga \& kebugaran jasmani,

2. Bimbingan mental \& psikososial ; Ceramah agama , Kajian Al Qur'an, hadits, Bimbingan ibadah ,

3. Bimbingan Sosial; Pengetahuan tentang pengembangan kepribadian \& tingkah laku, Kegiatan sosialisasi dengan lingkungan

4. Bimbingan Pelatihan Ketrampilan; Menjahit, Menari, Kristik ,Ternak lele, Warung koperasi ,Salon dan potong rambut, Latihan musik / band

5. Bimbingan Individu ; Konseling, Terapi sosial

6. Bimbingan kelompok; Konseling kelompok, Dinamika kelompok

5) Tahap Pasca Pelayanan (Termination)

Penghentian pelayanan terhadap penerima manfaat anak-anak usia sekolah di Balai Rehabilitasi Sosial Woro Wiloso Salatiga akan berakhir apabila anak-anak penerima manfaat telah selesai menerima tahapan pelayanan yang diberikan yaitu sampai anak lulus sekolah SMU/SMK .

6) Monitoring dan Evaluasi

Dalam rangka efektifitas dan efisiensi pelayanan kesejahteraan sosial, dilakukan kegiatan monitoring dan evaluasi terhadap :

Monitoring dan Evaluasi proses

Seluruh proses pelayanan kesejahteraan sosial yang dilaksanakan senantiasa dimonitoring sejak tahap awal sampai akhir, agar pelayanan yang diberikan senantiasa dapat terevaluasi sehingga diharapkan dapat berjalan dengan lancar dan maksimal sesuai rencana program kegiatan.

Monitoring dan Evaluasi Hasil 
Pencapaian yang dihasilkan dalam pelaksanaan kegiatan dimonitor perkembangannya dan dievaluasi apakah tujuan pelayanan dalam rangka mewujudkan kesejahteraan sosial anak dalam Balai tercapai.

2. Pelayanan Kesejahteraan Sosial untuk Penerima Manfaat Balita Terlantar7)

a. Penerimaan penerima manfaat balita terlantar

Penerimaan balita terlantar dilakukan dengan cara :

Jemput bola ( proaktif dan reaktif ) ketempat / daerah diketahui adanya balita terlantar dan perlu segera mendapatkan pelayanan, meliputi seluruh wilayah Jawa Tengah dan sekitarnya.

Penerimaan balita terlantar yang diserahkan langsung ke Balai / Unit Rehabilitasi Sosial Wiloso Tomo Salatiga, baik oleh masyarakat, keluarga balita terlantar, Kepolisian, Rumah Sakit, Dinas / instansi terkait.

2) Bentuk pelayanan balita terlantar meliputi :

a. Penyerahan anak balita terlantar ( bermasalah ) kepada Balai Rehabilitasi Sosial oleh orang tua biologis (kandung), masyarakat, Dinas Sosial dan instansi terkait untuk menjadi anak negara dan dapat dilakukan adopsi atau pengangkatan anak oleh Calon Orang Tua angkat sesuai dengan ketentuan perundang-undangan yang berlaku.

b. Pengangkatan Anak antar Warga Negara Indonesia.

3) Jenis Pelayanan Balita di Unit Resos Wiloso Tomo Salatiga

Setelah bayi diterima sebagai penerima manfaat dan masuk asrama, maka proses pelayanannya meliputi ;

a) Pelayanan Penyantunan

7 ) Wawancara dengan Valentino Waas, S.Sos selaku Kepala Balai Resos Woro Wiloso Salatiga, Tgl. 18 Februari 2013 
$>$ Pengasramaan

> Pemberian susu formula, makanan pendamping, buah, sneck yang diberikan sesuai dengan perkembangan usia anak dan standard gizi yang direkomendasikan oleh ahli gizi dari Puskesmas Sidorejolor 03 Salatiga

> Pemeliharaan dan pemantauan kesehatan anak ;

* Adanya kunjungan / visit dokter

* Pemberian imunisasi yang disesuaikan antara jenis imunisasi dengan tahap usia anak

- Pemantauan tumbuh kembang anak dan Pemeriksaan kesehatan

b) Penerbitan Akte Kelahiran balita

c) Alat Permainan Edukatif ( APE )

Untuk mengembangkan motorik dan kecerdasan anak balita disediakan alat permainan edukatif meskipun masih sederhana

d) Pelayanan Proses Pengangkatan Anak

c. Proses pengangkatan anak di Balai Rehabilitasi Sosial Woro Wiloso Salatiga

1)Calon orang tua angkat ( Cota ) menyerahkan persyaratan pengangkatan anak berdasarkan Permensos RI Nomor : 110 /huk /2009

2)Adanya Calon anak angkat di balai yang diinginkan Cota untuk diadopsi, dengan latar belakang yang ada dan diketahui Cota

3)Home visit I oleh Pekerja Sosial dan Pegawai Balai Resos Woro Wiloso ke rumah Cota

4)Pembuatan laporan sosial untuk pengasuhan sementara , Cota dan Calon Anak Angkat (CAA)

5)Pengajuan permohonan penerbitan Surat Keputusan Ijin Pengasuhan sementara (minimal 6 bulan pengasuhan) kepada 
Kepala Dinas Sosial Provinsi Jawa Tengah untuk Calon orang tua angkat yang telah dikunjungi dan memenuhi persyaratan dengan dilampiri berkas persyaratan pengangkatan

6)Penerbitan Surat Keputusan Ijin Pengasuhan anak dari Kepala Dinas Sosial Provinsi Jawa Tengah dilanjutkan penyerahan anak untuk pengasuhan sementara (minimal 6 bulan pengasuhan) dari Balai Resos Woro Wiloso kepada COTA, dengan penanda tanganan Berita acara penyerahan anak untuk pengasuhan sementara dan perjanjian asuhan anak

7)Pengurusan akte kelahiran anak balita oleh Balai Resos Woro Wiloso Salatiga ke Dinas Kependudukan dan Pencatatan Sipil Salatiga

8)Home visit II oleh Balai Resos Woro Wiloso Salatiga kepada COTA dan CAA dalam pengasuhan sementara

9)Laporan sosial Cota dan CAA untuk pengangkatan anak

10) Pengajuan permohonan Rekomendasi Pengangkatan Anak oleh COTA kepada Dinas Sosial Ketenagakerjaan dan Transmigrasi Salatiga

11)Pengajuan permohonan ijin pengangkatan anak ke Dinas Sosial Provinsi Jawa Tengah dengan dilampiri berkas yang diperlukan

12)Sidang Tim PIPA ( Pertimbangan Ijin Pengangkatan Anak ) Provinsi Jawa Tengah

13)Penerbitan Surat Keputusan Ijin Pengangkatan Kepala Dinas Sosial Provinsi Jawa Tengah

14)Penandatanganan Berita acara Penyerahan anak untuk pengangkatan oleh Kepala Balai Resos Woro Wiloso Salatiga dan Cota

15) Proses pengajuan permohonan pengangkatan anak ke Pengadilan Negeri atau Pengadilan Agama Salatiga 
d. Hasil Pelaksanaan Pelayanan, Penyantunan dan Pengangkatan anak Balita terlantar

Hasil pelaksanaan Pelayanan, Penyantunan dan Pengangkatan anak balita terlantar di Balai Resos Woro Wiloso Salatiga mulai Januari 2008 s/d Desember 2012 Secara kuantitatif adalah sbb.:

1. Penerimaan Balita Terlantar = 105 anak

2. Telah dikembalikan kepada orang tua kandung atau Keluarga untuk diasuh atau dirawat sendiri $\quad=14$ anak

3. Meninggal dunia karena penyakit bawaan = 2 anak

4. Dalam asuhan Orang Tua Angkat berdasarkan Penetapan Pengadilan $\quad=51$ anak

5. Dalam asuhan COTA untuk pengasuhan sementara $=23$ anak

6. Dalam asuhan Unit Resos Wiloso Tomo = 15 anak

Sedangkan secara kualitatif hasil dari pelayanan dan pengangkatan anak balita adalah :

1) Dengan adanya pelayanan terhadap balita terlantar maka merupakan kontribusi penting dalam perlindungan terhadap anak sebagai kader potensi penerus bangsa baik dari ancaman masa depan buruk, keterlantaran ataupun ancaman keselamatan jiwa anak yang lahir karena tidak diharapkan;

2) Pelaksanaan pengangkatan yang dilaksanakan telah mampu melakukan seleksi terhadap Calon orang tua angkat sesuai prosedur yang berlaku dan balita terlantar mendapatkan orang tua angkat yang tepat'

3) Dari kegiatan pelayanan pengangkatan anak balita telah berhasil menjalin relasi yang efektif sehingga mencipatakan pelayanan yang optimal . . kerjasama dilakukan dengan para stake holder diantaranya adalah; Dinas Kependudukan dan 
Pencatatan Sipil Salatiga, Pengadilan Negeri Salatiga, Pengadilan Agama, Dinas Sosial Salatiga;

2. Hambatan - Hambatan

Hambatan-hambatan yang ada dalam pelaksanaan pelayananan di Balai Resos Woro Wiloso Salatiga adalah ${ }^{8}$ :

1) Keterbatasan Sumber Daya manusia ( SDM ) baik secara kuantitatif maupun kualitatif artinya yang sesuai dengan latar belakang pendidikan Pekerjaan Sosial ;

2) Sarana prasarana yang relative bagus namun masih kurang optimal ;

3) Pelayanan yang diberikan terhadap penerima manfaat anak usia sekolah masih terbatas meluluskan Sekolah Menengah Atas saja belum dapat mengantarkan anak pada kemandirian secara penuh ;

4) Belum adanya program follow up seperti monitoring lanjut pada kegiatan pengangkatan anak bagi balita yang sudah diangkat syah secara hukum melalui pengadilan setelah berada pada pengasuhan, pemeliharaan orang tua angkat.

3. Upaya - Upaya Dalam Mengatasi Hambatan ${ }^{9}$

1) Dalam mengatasi keterbatasan SDM yang ada, maka dengan jumlah pegawai yang terbatas dalam melakukan pelayanan dilakukan pembagian kerja yang efisien dan efektif

2) Untuk meningkatkan kualitas pegawai maka diberikan kesempatan seluas-luasnya bagi setiap pegawai untuk mengembangkan diri dengan melanjutkan pendidikan formal , kesempatan mengikuti pendidikan dan pelatihan ataupun

8 ) Wawancara dengan Valentino Waas,S.Sos, selaku Kepala Balai Resos Woro Wiloso Salatiga, Tgl. 18 Februari 2013

9 ) idem 
mengikuti seminar dan bimbingan teknis yang menunjang tugas sehari-hari pegawai

3) Untuk memenuhi sarana prasarana yang dibutuhkan dilakukan upaya dengan cara mengoptimalkan sarana yang ada sebaik mungkin dengan memelihara, mengefektifkan penggunaannya serta dilakukan upaya pengajuan pengadaan ke Dinas Sosial provinsi Jawa Tengah

4) Upaya yang dilakukan Balai dalam mengantarkan kemandirian anak usia sekolah setalah lulus sekolah dengan kondisi yang ada adalah dengan berusaha menjalin kerjasama dengan pihak LPK;

5) Dengan belum adanya program khusus dari dinas terhadap kegiatan follow up pengangkatan anak, maka upaya yang dilakukan adalah dengan cara melakukan monitoring dan evaluasi lanjutan secara insidentil ;

\section{PENUTUP}

\section{Kesimpulan}

Dalam Pelaksanaan Pelayanan Kesejahteraan Sosial terhadap anakanak dan balita terlantar, Balai Resos Woro Wiloso Salatiga menemui beberapa hambatan baik yang bersifat teknis proses pelayanan maupun kondisional lembaga. Namun dengan paradigma kerja yang dimiliki oleh unsur pimpinan dan pegawai berspektif melakukan pelayanan yang terbaik untuk kesejahteraan anak-anak maka semua hambatan yang ada dapat diatasi dengan baik, Balai Resos Woro Wiloso Salatiga dapat mengefektifkan semua potensi yang ada sebaik mungkin untuk menghasilkan pelayanan sesuai dengan tujuan yang telah ditetapkan. Pelayanan di Balai Resos Woro Wiloso Salatiga dan upaya mengatasi hambatan yang ada dapat dilakukan dengan baik, juga karena adanya dukungan penuh 
dari Dinas Sosial Provinsi Jawa Tengah yang selalu memonitor dan mengevaluasi kinerja Balai serta memberikan pembinaan terhadap pegawai dan teknis pelayanan, serta dari stakeholder yang ikut peduli dan membantu kelancaran pelayanan yang dijalankan Balai.

\section{Saran}

Pelayanan Kesejahteraan Sosial yang telah dilaksanakan oleh Balai Resos Woro Wiloso Salatiga sudah baik, namun untuk memberikan pelayanan yang lebih optimal dan terwujudnya kesejahteraan sosial anak yang mampu meraih masa depan dan mandiri , Balai Resos Woro Wiloso Salatiga tidak hanya puas dan berhenti pada tahapan hasil pelayanan saat ini tapi harus lebih mampu meningkatkan kualitas pelayanan agar anak benar-benar dapat menjadi generasi yang potensial penerus perjuangan bangsa. Adanya hambatan yang ditemui meskipun sudah ada upaya mengatasinya, namun diharapkan untuk pelayanan kesejahteraan sosial kedepan Balai Resos Woro Wiloso dapat berupaya agar faktor yang menjadi hambatan saat ini bisa berubah menjadi sumber potensi demi terwujudnya kesejahteraan sosial anak yang optimal di Jawa Tengah. 


\section{DAFTAR PUSTAKA}

\section{A. Buku}

A.S. Moenir,1983, Pendekatan Manusia dan Organisasi Terhadap Pembinaan Kepegawaian, Gunung Agung, Jakarta;

Meta Suryani, Anis Mashdurohatun, Penegakan Hukum Terhadap Eksistensi Becak Bermotor Umum (Bentor) Berdasarkan Undang-Undang Nomor 22 Tahun 2009 Tentang Lalu Lintas Dan Angkutan Jalan, Jurnal Pembaharuan Hukum, Volume III No. 1 Januari - April 2016;

Bubb, S., \& Earley, P, 2004, Managing teacher workload, Paul Chapman Publishing, London

Byars L \& Rue LW, 1991, Management (skills and application), Irwin McGraw Hill, Boston

Dean, Joan. 1991, Professional Development in School, Ohio University Press, Philadelphia

Dedi Supriadi, 1998, Mengangkat Citra dan Martabat Guru, Adicita Karya Nusa, Yogyakarta

Handoko, Hani T, 2001, Manajemen Personalia dan Sumber Daya Manusia, BPFE, Yogyakarta

IG Wursanto, 1988, Dasar-Dasar Manajemen Personalia, Pustaka Dian Cet 2, Jakarta,

I.S. Livine, 1980, Teknik Memimpin Pegawai dan Pekerja. Terjemahan oleh Iral Soedjono, Cemerlang, Jakarta

Jalaluddin, 2003, Teologi Pendidikan, PT. RajaGrafindo Persada, Jakarta Jalaluddin, 2003, Teologi Pendidikan, PT. RajaGrafindo Persada, Jakarta

Jean D. Grambs dan C. Morris Mc Clare. 2005. Foundation of teaching, An Introduction to Modern Education, Mac education, South Melbourne

Latham GP \& Wexley KN, 1981, Increasing productivity through performance appraisal, Addison-Wesley Publishing Company, Michigan Styate University

Laurence D. Hazkew dan Jonathan C. Mc Lendon, 2001, This is Teaching, Addison wasley Longman Inc, New York

Lexy J. Moleong. 2000. Metodologi Penelitian Hukum. Citra Aditya 
Bakti. Bandung

Martin, R. E, Wood, G.H. \& Stevens. E.W, 1988, An introduction to teaching, Allyn \& Bacon Inc, Boston

Moch.Faizal Salam, 2003, Penyelesaian Sengketa Pegawai Negeri Sipil di Indonesia Menurut Undang-Undang No.43 Tahun 1999, Mandar Maju, Bandung

Moekijat, 1989, Manajemen Kepegawaian, Alumni, Bandung.

Moh. Mahfud, 1988, Hukum Kepegawaian Indonesia, Liberty, Yogyakarta

Mulyasa. 2007, Menjadi Guru Profesional, T Remaja Rosdakarya. Bandung

Nainggolan, 1987, Pembinaan Pegawai Negeri Sipil, PT Pertja, Jakarta

Nitisemito Alex.S., 1988, Manajemen Personalia, Ghalia Indonesia, Jakarta.

\section{B. Perundang - Undangan}

Undang - Undang Republik Indonesia Nomor 20 Tahun 2003 tentang Sistem Pendidikan Nasional

Peraturan Pemerintah Republik Indonesia Nomor 53 Tahun 2010 tentang Disiplin Pegawai Negeri Sipil

Peraturan Pemerintah Republik Indonesia Nomor 74 tahun 2008 tentang Guru dan. Dosen

Peraturan Menteri pendidikan Nasional Nomor 39 Tahun 2009 tentang Beban Kerja Guru dan Pengawas Sekolah.

Peraturan Bupati Pemalang Nomor 26 tahun 2012 tentang Hari dan Jam Kerja PNS Pemerintah Kabupaten Pemalang. 